\title{
Sistema de geoespacialização da demanda de irrigação suplementar para o Estado de Minas Gerais II - Avaliação
}

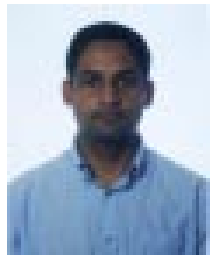

Marcos O. Santana ${ }^{2}$, Aristides Ribeiro ${ }^{3}$ \& Gilberto C. Sediyama ${ }^{4}$

\author{
1 Parte da Dissertação de Mestrado apresentada pelo primeiro autor na UFV. Viçosa, MG \\ 2 DEA/UFV. Viçosa, MG. Fone: (31) 3899-1905, Fax: (31) 3899-2735. E-mail: santana@alunos.ufv.br (Foto) \\ ${ }^{3}$ DEA/UFV. Viçosa, MG. Fone: (31) 3899-1906, E-mail: ribeiro@ufv.br \\ ${ }^{4}$ DEA/UFV. Viçosa, MG. Fone: (31) 3899-1905, E-mail: sediyama@ufv.br
}

Protocolo 125 - 29/8/2002 - Aprovado em 21/2/2003

\begin{abstract}
Resumo: O propósito primeiro deste trabalho foi avaliar o sistema de regionalização da demanda de irrigação suplementar das principais culturas irrigadas no Estado de Minas Gerais. A performance do sistema, denominado IRGNET, foi avaliada calculando-se a estimativa da demanda de irrigação suplementar acumulada para Minas Gerais, no ano de 1999, em duas épocas de plantio, para a cultura do feijoeiro. Calculou-se a demanda pelo sistema desenvolvido e por meio do método climatológico proposto por Camargo (1971) e se estimou o volume total de água utilizada na irrigação do feijoeiro em todos os municípios de Minas Gerais, nas duas épocas de plantio. Também, comparou-se a estimativa da evapotranspiração de referência para Viçosa, MG, no ano de 1999, calculada pelos métodos do Tanque Classe A e de Penman-Monteith, utilizados no sistema. Observou-se que as estimativas da demanda de irrigação suplementar acumulada, calculada pelo sistema, foram mais elevadas que as estimativas do modelo climatológico proposto por Camargo. O volume total de água para irrigação da cultura do feijoeiro em Minas Gerais no plantio de 10 de maio de 1999, foi de $611.720 .830 \mathrm{~m}^{3}$ e, no plantio de 15 de setembro, de $686.660 .480 \mathrm{~m}^{3}$. O método do Tanque Classe A subestimou a evapotranspiração de referência em $7,6 \%$.
\end{abstract}

Palavras-chave: irrigação suplementar, balanço hídrico, sistema de informações geográficas, internet

\section{Geospatialization system for demand of supplementary irrigation in the State of Minas Gerais II - Evaluation}

\begin{abstract}
This study had the aim to evaluate a regionalization system of supplementary irrigation demand for the main irrigated crops in the State of Minas Gerais. The performance of the so-called IRGNET system was evaluated by assessment of the accumulated supplemental irrigation demand for Minas Gerais during the year of 1999, for two planting dates, for bean (dry) crop. The water demand was calculated by the IRGNET system and by a climatic method proposed by Camargo (1971). The total volume of water used for irrigation of a bean crop with all potential irrigated area of Minas Gerais was estimated for two planting dates. The estimated reference crop evapotranspiration for Viçosa, Minas Gerais, was also compared for the year of 1999, calculated by means of the soil water balance, Class A pan evaporation and the Penman-Monteith method. It was observed that the accumulated supplementary irrigation demand was higher than the estimates obtained by the climatic model suggested by Camargo. The total water volume for the irrigation of bean crop in the State of Minas Gerais was $611,720,830 \mathrm{~m}^{3}$ for the planting period of $1^{\text {st }}$ May, while $686,660,480 \mathrm{~m}^{3}$ were found for the cultivation period of $15^{\text {th }}$ September. The Class A pan evaporation method underestimated the reference crop evapotranspiration by $7.6 \%$.
\end{abstract}

Key words: supplemental irrigation, water balance, geographic information system, internet

\section{INTRODUÇÃO}

O objetivo principal da irrigação é suprir as necessidades hídricas da planta durante seu crescimento e desenvolvimento, recolocando no solo a quantidade de água consumida pela evapotranspiração. A irrigação torna possível mais de uma safra anual, permitindo o aproveitamento intensivo do solo, inclusive dos cerrados e das regiões secas, minimizando as incertezas do clima e elevando substancialmente a produtividade agrícola.

Embora a irrigação seja uma técnica alternativa que visa ao aumento da produtividade das culturas, sobretudo em regiões áridas e semi-áridas, esta técnica causa grande impacto na disponibilidade dos mananciais de água, em virtude do grande consumo de água requerido nos sistemas de irrigação, 
especialmente em regiões com elevada concentração de áreas irrigadas e, principalmente, na época da seca (Costa, 1991).

Um dos principais problemas que ocorrem com freqüência na agricultura, é a baixa eficiência com que são utilizados os recursos disponíveis. Uma produção eficiente e rentável deve constituir um dos primeiros objetivos da empresa agrícola. Para atingir tal fim, deve-se utilizar, racionalmente, os recursos disponíveis, de tal maneira que sejam atingidos os mais altos níveis de produtividade econômica (Frizzone, 1995).

Uma forma muito utilizada para se determinar quanto irrigar, é estimar a necessidade de água a partir do balanço hídrico dos solos (Reichardt, 1990). O balanço de água no solo é um método de estimativa da disponibilidade hídrica no solo para as plantas pela contabilização das entradas e saídas de água no sistema solo-água-planta. Ele está fundamentado no princípio da conservação de massa, em que a transferência da massa de água, em determinado volume de controle, com capacidade finita de armazenamento e em determinado intervalo de tempo, pode ser determinada pelas variações nos fluxos de água no solo (Bergamaschi, 1992). A principal variável de entrada é a precipitação e o mais importante componente de saída, para fins de manejo de irrigação, é a evapotranspiração.

Nos últimos anos, ocorreram avanços impressionantes nos ramos da ciência que estudam os recursos naturais, tais como Geologia, Pedologia, Hidrologia, Meteorologia e Ecologia, e se tem gerado novos dados passíveis de serem mapeados. Com os crescentes avanços, foi gerada uma soma muito grande de dados passíveis de serem representados espacialmente. Assim, tornou-se praticamente impossível mapear esses dados apenas com os recursos manuais, o que levou ao desenvolvimento de ferramentas automáticas e computadorizadas para manipulação desses dados, os sistemas de informações geográficas (SIG). Atualmente, os SIGs têm-se tornado uma ferramenta poderosa na manipulação de dados espaciais e seus atributos, possibilitando a simulação, a modelagem e a visualização de informações associadas aos mapas de áreas de cultivo e fornecendo subsídios ao processo de tomada de decisões.

Nos anos recentes, os SIGs têm sido utilizados extensivamente para suprir dados de entrada espaciais para qualidade de água e modelagem hidrológica, devido à sua capacidade de armazenar, recuperar, manipular, analisar e mostrar dados geograficamente referenciados. Os avanços recentes da tecnologia computacional produziram SIGs com melhores resoluções nas imagens e com manipulação mais rápida. Fontes de dados digitais georreferenciados têm-se tornado cada vez mais acessíveis. Os recentes progressos nos SIG têm conduzido a análises dos mais diferentes tipos de dados espacialmente distribuídos. Sistemas avançados agora são capazes de sobrepor análises complexas. Essas técnicas de análise espacial deram uma nova dimensão à tecnologia SIG, permitindo aos usuários empregar esse sistema para ajudar a analisar e interpretar bancos de dados espaciais desenvolvidos para uma diversidade aparentemente ilimitada de aplicações (Verma et al., 1998).

Knox et al. (1997) utilizaram técnicas de SIG para mapear o requerimento total anual de água para irrigação das principais culturas irrigadas no Reino Unido. Eles empregaram um modelo de balanço hídrico diário para cálculo da irrigação necessária de oito culturas, em três tipos de solo, com texturas distintas.
Foram utilizados dados climáticos de 11 estações meteorológicas representativas, sendo esta uma informação muito importante para o planejamento dos recursos hídricos.

Vários são os serviços que o agricultor pode obter através da Internet, como: indicativos financeiros sobre o mercado agrícola, informações sobre manejo de culturas agrícolas e previsão de tempo, dentre outros. Waskman \& Harkin (1999) comparando os serviços de informações agrícolas disponibilizados em sistemas de telemetria desenvolvidos na década de 80 com as aplicações existentes na Internet, concluíram recentemente que para o usuário final os avanços obtidos eram muito questionáveis, já que os investimentos em conexão com a Internet eram relativamente elevados e os benefícios alcançados seriam difíceis de serem medidos. Há de se levar em consideração que os avanços na Internet são espantosamente rápidos, de forma que a realidade atual é bem mais favorável. Apesar de tudo, o sucesso do uso da Internet na agricultura está associado à existência de produtos adequados à realidade do agricultor, ao treinamento do usuário e ao acesso à rede. Para isso, a parceria com órgãos extensionistas é imprescindível, tanto no balizamento dos produtos a serem gerados quanto no treinamento dos usuários ao acesso às informações via Internet.

Ante o exposto objetivou-se, com este trabalho, avaliar a performance de um sistema de regionalização da demanda de irrigação suplementar das principais culturas irrigadas no Estado de Minas Gerais e a viabilidade de sua disponibilização via rede mundial de computadores.

\section{MATERIAL E MÉTODOS}

\section{Região de estudo}

A região de estudo abrangeu todo o Estado de Minas Gerais, situado na Região Sudeste do País, entre os paralelos $14^{\circ} 13^{\prime} \mathrm{e}$ $22^{\circ} 55^{\prime}$ de latitude Sul e os meridianos $39^{\circ} 51^{\prime}$ e $51^{\circ} 02^{\prime}$ de longitude Oeste. O Estado está dividido em mesorregiões geográficas (Figura 1) consideradas para analisar a distribuição geográfica da demanda de irrigação suplementar.

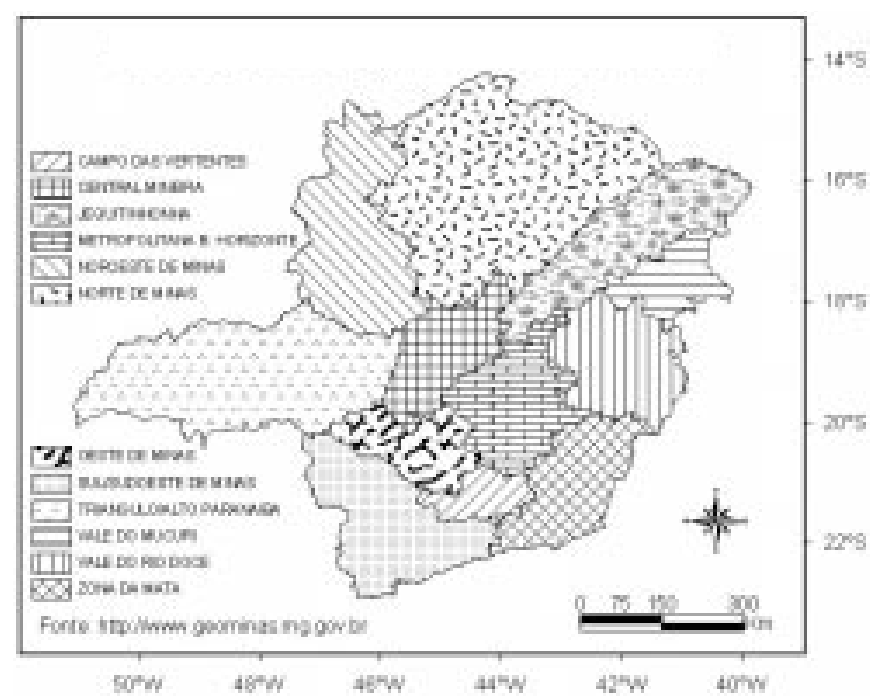

Figura 1. Mesorregiões geográficas do Estado de Minas Gerais (www.geominas.mg.gov.br) 


\section{O Sistema IRGNET}

Desenvolveu-se um sistema de geoespacialização da demanda de irrigação suplementar para o Estado de Minas Gerais (IRGNET) para disponibilizar na Internet, mapas de evapotranspiração de referência (ETo) e de precipitação, além de um programa computacional para calcular o balanço de água no solo e determinar a demanda de irrigação suplementar, para qualquer coordenada geográfica do Estado de Minas Gerais. Tais informações são disponibilizadas via Internet, com três atualizações semanais, juntamente com o programa para o cálculo do balanço hídrico.

O sistema IRGNET fundamenta-se no balanço de água diário do solo para o cálculo da demanda de irrigação suplementar (Bernardo, 1995). Para a estimativa da evapotranspiração de referência utilizou-se a equação de Penman-Monteith padrão FAO (Allen et al., 1998). Uma descrição mais detalhada do funcionamento do sistema pode ser encontrada em Santana (2000).

\section{Base de dados}

Os dados meteorológicos que alimentam o sistema são disponibilizados na Internet a cada $3 \mathrm{~h}$ através do Centro de Missão de Coleta de Dados (CMCD) do Instituto Nacional de Pesquisas Espaciais (INPE).

Utilizaram-se para análise do sistema no ano de 1999, além dos dados meteorológicos do CMCD/INPE, dados de 30 estações climatológicas telemétricas e 52 estações pluviométricas da Companhia Energética do Estado de Minas Gerais (CEMIG). Em breve, essa base de dados será incorporada ao sistema IRGNET. Também foram utilizados dados de 39 estações climatológicas principais do Instituto Nacional de Meteorologia (INMET) do ano de 1999.

\section{Balanço hídrico proposto por Camargo (1971)}

Fez-se uma comparação entre o modelo de balanço hídrico diário utilizado no sistema (Bernardo, 1995) e o balanço hídrico proposto por Camargo (1971). Da mesma forma que no modelo de balanço hídrico diário, neste foram utilizados valores diários de precipitação; entretanto, o cálculo da $\mathrm{ET}_{0}$ foi baseado em valores normais da temperatura média mensal. A equação para o cálculo da $\mathrm{ET}_{0}$ foi uma adaptação da equação de Thornthwaite (1948) citado por Camargo (1971) e é dada pela seguinte equação:

$$
\mathrm{ET}_{\mathrm{o}}=\mathrm{Q}_{\mathrm{o}} \mathrm{TF} \mathrm{n}_{\mathrm{d}}
$$

em que:

$\mathrm{Q}_{0}$ - radiação solar extraterrestre, $\mathrm{mm} \mathrm{d}^{-1}$

$\mathrm{T}$ - temperatura média do período considerado, ${ }^{\circ} \mathrm{C}$

$\mathrm{F}$ - fator de ajuste (função da temperatura média anual)

$\mathrm{n}_{\mathrm{d}}$ - número de dias do período

Camargo (1971) considerou o balanço com turno de regas mensal, quinzenal, decendial ou qüinqüidial. Nas análises efetuadas, foi utilizado o turno de rega de 5 dias. Esse intervalo foi recomendado para solos com capacidade de água disponível (CAD) de $80 \mathrm{~mm}$ e água prontamente disponível para as plantas (AD) de $25 \mathrm{~mm}$. A ET o foi calculada utilizando-se a temperatura mensal das normais climatológicas e dividida proporcionalmente quanto ao número de dias do período que, apesar de ser cinco, pode variar de três a seis dias, dependendo do mês e do ano. A dotação de rega (DR) isto é, a quantidade de água a ser utilizada em cada aplicação, deve ser de 25 a 50\% de AD. As Eq. 2 a 5 indicam como é definido o valor da prescrição da rega a ser adotada.

$$
\begin{gathered}
\mathrm{AD}_{(\mathrm{i})}=\mathrm{AD}_{(\mathrm{i}-1)}+\mathrm{P}_{(\mathrm{i})}+\mathrm{R}_{(\mathrm{i})}-\mathrm{ETc}_{(\mathrm{i})} \\
\mathrm{AD}_{(\mathrm{i})}=25 \text { se } \mathrm{AD}_{(\mathrm{i})}>25 \\
\mathrm{DR}=\mathrm{AD}_{(\mathrm{i}-1)}-\mathrm{AD}_{(\mathrm{i})} \text { se } \mathrm{AD}_{(\mathrm{i})} / 4<\mathrm{DR}<\mathrm{AD}_{(\mathrm{i})} / 2 \\
\mathrm{DR}=2 \times \mathrm{AD}_{(\mathrm{i})} / 2 \text { se } \mathrm{AD}_{(\mathrm{i})}=0
\end{gathered}
$$

em que:

$$
\begin{array}{ll}
\mathrm{AD}_{(\mathrm{i})} & \text { - água disponível no período } \mathrm{i}, \mathrm{mm} \\
\mathrm{AD}_{(\mathrm{i}-1)} & \text { - água disponível no período i-1, } \mathrm{mm} \\
\mathrm{P}_{(\mathrm{i})} & \text { - precipitação no período i, } \mathrm{mm} \\
\mathrm{R}_{(\mathrm{i})} & \text { - rega no período i, mm } \\
\mathrm{ETc}_{(\mathrm{i})} & \text { - evapotranspiração no período i, } \mathrm{mm}\left[\mathrm{ETc}=\mathrm{kc} \mathrm{ET}_{\mathrm{o}}\right]
\end{array}
$$

Foram calculados o balanço hídrico diário e o balanço hídrico proposto por Camargo (1971) para a cultura do feijoeiro, em duas épocas de plantio (1ํo de maio de 1999 e 15 de setembro de 1999). Posteriormente, fez-se a espacialização para Minas Gerais, da demanda de irrigação suplementar acumulada nos dois períodos de estudo, calculada pelos dois métodos de balanço hídrico. Também, foi espacializada a diferença entre a demanda de irrigação calculada pelo método do balanço hídrico de Camargo (1971) e do balanço hídrico calculado pelo sistema IRGNET.

\section{Estimativa do volume da água para irrigação}

Foram realizadas a estimativa e a espacialização do requerimento de água para irrigação, por município, no ano de 1999. Para tanto, utilizou-se o mapa vetorial com os limites dos municípios do Estado de Minas Gerais, originado da importação de arquivos disponíveis na página da Internet do projeto Geominas (www.geominas.mg.gov.br). Os valores da área irrigada por município foram obtidos do Censo Agropecuário de Minas Gerais de 1995/1996 (FIBGE, 1998).

Foram feitas análises em duas épocas de plantio (1ํㅡe maio de 1999 e 15 de setembro de 1999) considerando-se que toda a área irrigada era cultivada com feijão (justificada por se tratar de uma das culturas mais irrigadas em Minas Gerais, além de ser plantada mais de uma vez por ano).

Os valores de demanda de irrigação suplementar foram calculados pelo método do balanço hídrico diário (Bernardo, 1995) para as 145 estações com disponibilidade de dados. Posteriormente, esse resultado foi interpolado através do módulo Interpol do IDRISI 3.2, que utiliza um interpolador linear em que o peso a ser interpolado é dado por uma média ponderada, a qual usa o valor dos pontos de controle mais próximos ponderados pelo inverso da distância elevado a determinado expoente. $\mathrm{O}$ interpolador do IDRISI emprega um 
raio de busca variável que pode utilizar os seis pontos amostrados mais próximos, ou todos os pontos de controle. Neste estudo optou-se pela primeira opção e o expoente da função da distância igual a 4 que, em estudos preliminares, apresentou melhores resultados para o caso em questão. $\mathrm{O}$ resultado da interpolação foi transformado em tabelas, através do módulo de exportação GRASSIDRIS e se desenvolveu uma rotina em Visual Basic 6.0, para ler essas tabelas e retornar ao valor médio da demanda de irrigação para todos os municípios de Minas Gerais. Esses valores foram multiplicados pela área irrigada para obter o volume de água requerido para irrigação $\mathrm{em}^{3}$ e os resultados foram utilizados para reclassificar os mapas de limites municipais obtendo-se, desta forma, os mapas de requerimento de irrigação para o feijoeiro por município.

\section{Análise da estimativa de evapotranspiração de referência}

Fez-se uma comparação para Viçosa, $\mathrm{MG}$, dos valores de $\mathrm{ET}_{\mathrm{o}}$ estimados pelo método FAO-Tanque Classe A, muito empregado no manejo de irrigação, com a estimativa de $\mathrm{ET}_{0}$, utilizando-se o método FAO Penman-Monteith como padrão. Os valores de evaporação do Tanque Classe A foram obtidos da estação climatológica principal do INMET de Viçosa, ao passo que os dados para o cálculo da $\mathrm{ET}_{\text {o }}$ pelo método de Penman-Monteith foram usados da Plataforma de Coleta de Dados do CMCD/INPE de Viçosa.

Realizaram-se análises de regressão linear e regressão linear passando pela origem e, como parâmetro comparativo, foi calculado o erro-padrão de estimativa (EPE) e o erro-padrão de estimativa ajustado (EPEA) qual seja:

$$
\mathrm{EPE}=\left[\frac{\sum_{\mathrm{i}=1}^{\mathrm{n}}\left(\mathrm{Y}_{\mathrm{i}}-\hat{\mathrm{Y}}_{\mathrm{i}}\right)^{2}}{\mathrm{n}^{\prime}}\right]
$$

em que $\mathrm{Y}_{\mathrm{i}}$ é a estimativa de $\mathrm{ET}$ o padrão no dia $\mathrm{i}, \hat{\mathrm{Y}}_{\mathrm{i}}$ é a estimativa de $\mathrm{ET}_{0}$ calculada pelo FAO-Tanque Classe A correspondente e n' é o número total de observações no ano de 1999. Para o cálculo do EPEA, o valor $Y_{i}$ é a estimativa ajustada pela origem. $\mathrm{O} E P E$ concede igual peso às diferenças absolutas entre os valores-padrão e estimados. Desta forma, os parâmetros EPE e EPEA serviram para indicar quão bem o método FAO Tanque Classe A estimou a $\mathrm{ET}_{\mathrm{o}}$ em relação ao padrão.

\section{RESULTADOS E DISCUSSÃO}

\section{Espacialização da demanda de irrigação suplementar}

Balanço hídrico calculado pelo sistema IRGNET: Nas Figuras 2A e B, mostram-se os mapas de lâmina acumulada de irrigação suplementar, em classes de $20 \mathrm{~mm}$, para todo o ciclo da cultura do feijoeiro, utilizando-se o balanço hídrico diário (método adotado no sistema desenvolvido) nas datas de plantio em 1ํ de maio (A) e 15 de setembro de 1999 (B) respectivamente. As duas classes de maior freqüência coincidiram em ambos os períodos de estudo (180 a 200 e 200 a 220 mm) com a ressalva de que no primeiro essas classes ocuparam $61 \%$ da área do Estado e, no segundo, apenas 34,3\%. No primeiro período, as duas classes de menores freqüências compreenderam o intervalo de 80 a $120 \mathrm{~mm}$, com $0,4 \%$ da área; no segundo período, $0,8 \%$ da área foram ocupados com a classe de $100 \mathrm{a}$ $120 \mathrm{~mm}$ e $5,1 \%$ com a classe de 280 a $300 \mathrm{~mm}$.

A.

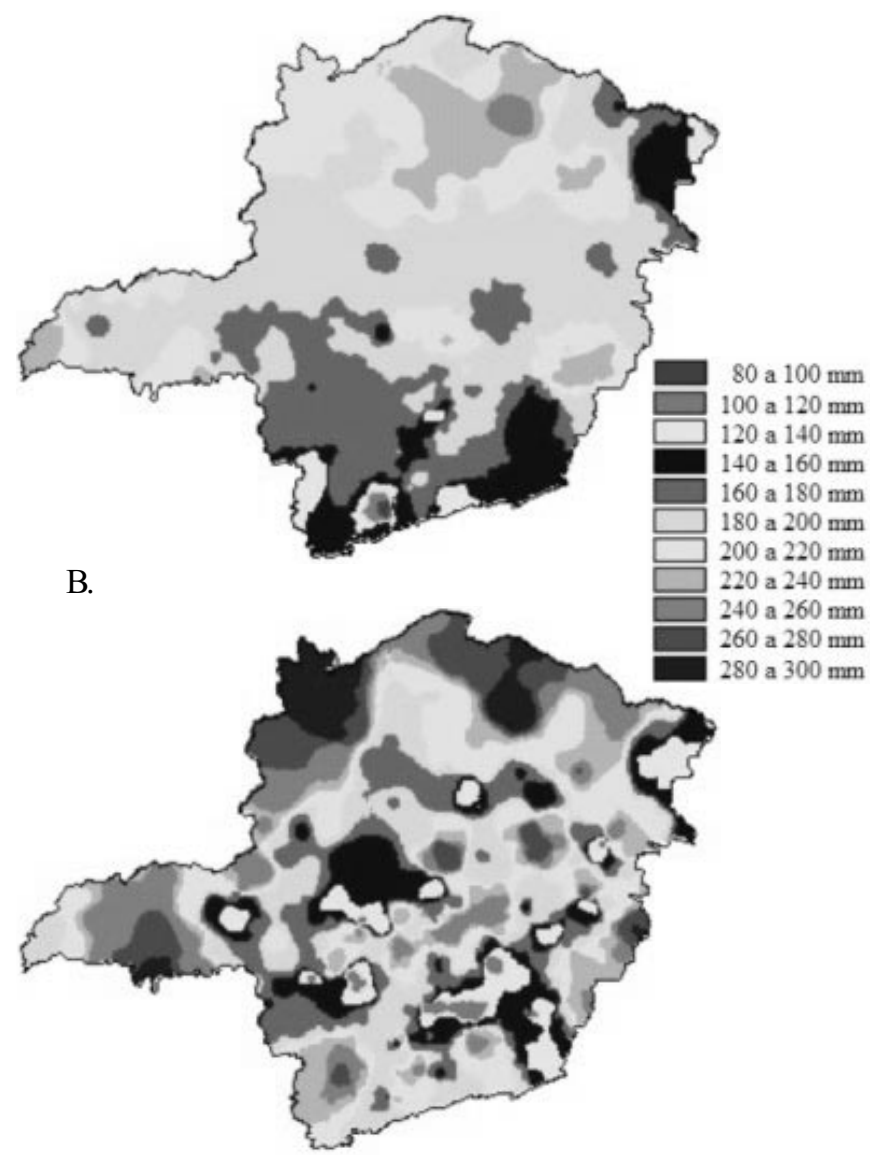

Figura 2. Lâmina de irrigação suplementar total calculada pelo balanço hídrico diário da cultura do feijão plantado em $1^{\circ} \mathrm{de}$ maio de 1999 (A) e em 15 de setembro de 1999 (B)

Analisando-se a distribuição espacial da demanda de irrigação no primeiro período, observou-se que as menores demandas se concentram nas regiões mineiras Sul, Sudoeste, Zona da Mata e parte do Jequitinhonha; já as áreas com demanda mais elevada, se situam nas regiões Norte, Vale do Rio Doce e Triângulo Mineiro. No segundo período, as maiores demandas se localizam no Norte e Noroeste de Minas, Triângulo Mineiro e Vale do Rio Doce e as mais baixas se concentram principalmente na região Oeste de Minas e Campo das Vertentes.

Balanço hídrico proposto por Camargo (1971): Nas Figuras $3 \mathrm{~A}$ e B, encontram-se os mapas de lâmina acumulada de irrigação suplementar, em classes de $20 \mathrm{~mm}$, para todo o ciclo da cultura do feijoeiro, utilizando-se o balanço hídrico proposto por Camargo (1971) para o manejo da irrigação, com o plantio em $1^{\circ}$ de maio (A) e 15 de setembro de 1999 (B) respectivamente.

Diverso do balanço hídrico diário, as duas classes de maior freqüência não foram coincidentes em ambos os períodos 
A.

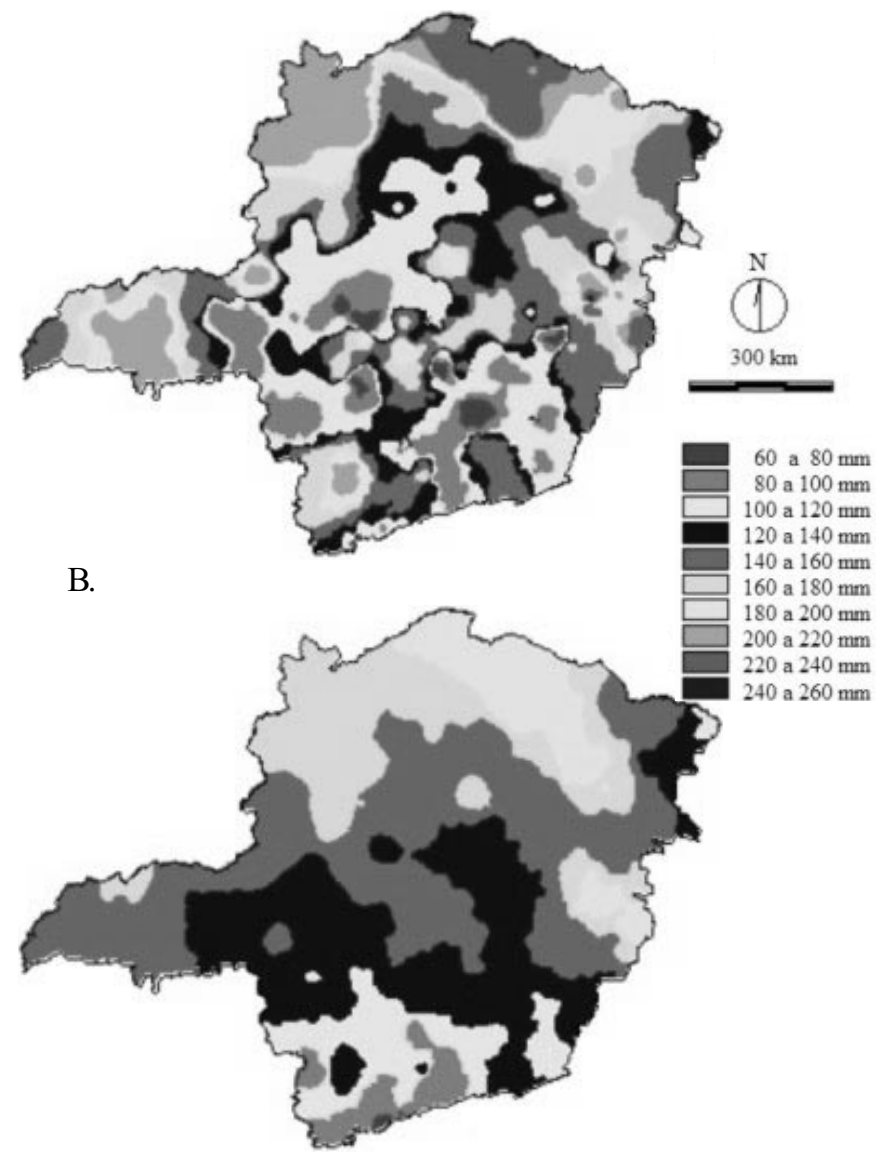

Figura 3. Lâmina de irrigação suplementar total calculada pelo balanço hídrico proposto por Camargo (1971) para a cultura do feijão plantado em 1을 de maio de 1999 (A) e em 15 de setembro de 1999 (B)

estudados. No plantio em 1을 de maio, as classes de maior freqüência de demanda de irrigação foram de 100 a 120 mm e de 140 a $160 \mathrm{~mm}$ somando, juntas, 35\% da área do Estado, enquanto no segundo período as duas maiores classes ficaram entre 120 e $160 \mathrm{~mm}$, ocupando $60,4 \%$ da área.

Da mesma forma que no balanço hídrico diário, as regiões Norte e Vale do Rio Doce apresentaram valores mais elevados de demanda, mas as áreas com baixa demanda foram bem mais freqüentes e se concentraram, no primeiro período, nas regiões da Zona da Mata, Campo das Vertentes, Oeste de Minas e Central Mineira e, no segundo período, no Sul e Sudoeste de Minas.

Diferença entre metodologias de balanço hídrico: As Figuras 4A e B, mostram a diferença entre o balanço hídrico de Camargo (1971) e o balanço hídrico diário da cultura do feijão plantado em $1^{\text {o }}$ de maio (A) e em 15 de setembro de 1999 (B) respectivamente. Verificou-se, em ambos os ciclos, que o balanço hídrico de Camargo (1971) subestimou a demanda de irrigação suplementar na maior parte do Estado. Na Tabela 1 observa-se que no plantio de $1^{\circ}$ de maio, em $71 \%$ da área do Estado a demanda foi subestimada em mais de $10 \mathrm{~mm}$ e superestimada em mais de $10 \mathrm{~mm}$, numa área de $10,4 \%$. No plantio de 15 de setembro, a área subestimada foi de $90,8 \%$ e a área superestimada, de apenas $2 \%$. As maiores diferenças negativas entre o balanço hídrico de Camargo (1971) e o balanço diário foram de 134 e $151 \mathrm{~mm}$ no plantio em $1 \%$ de maio e em 15 de setembro, respectivamente. Observou-se que as classes em que ocorreram as maiores diferenças se localizavam na região central do Estado no plantio de 1으 de maio; já no ciclo iniciado em 15 de setembro, tais classes se localizavam nas regiões do Vale do Rio Doce, Sul, Sudoeste e Norte de Minas.

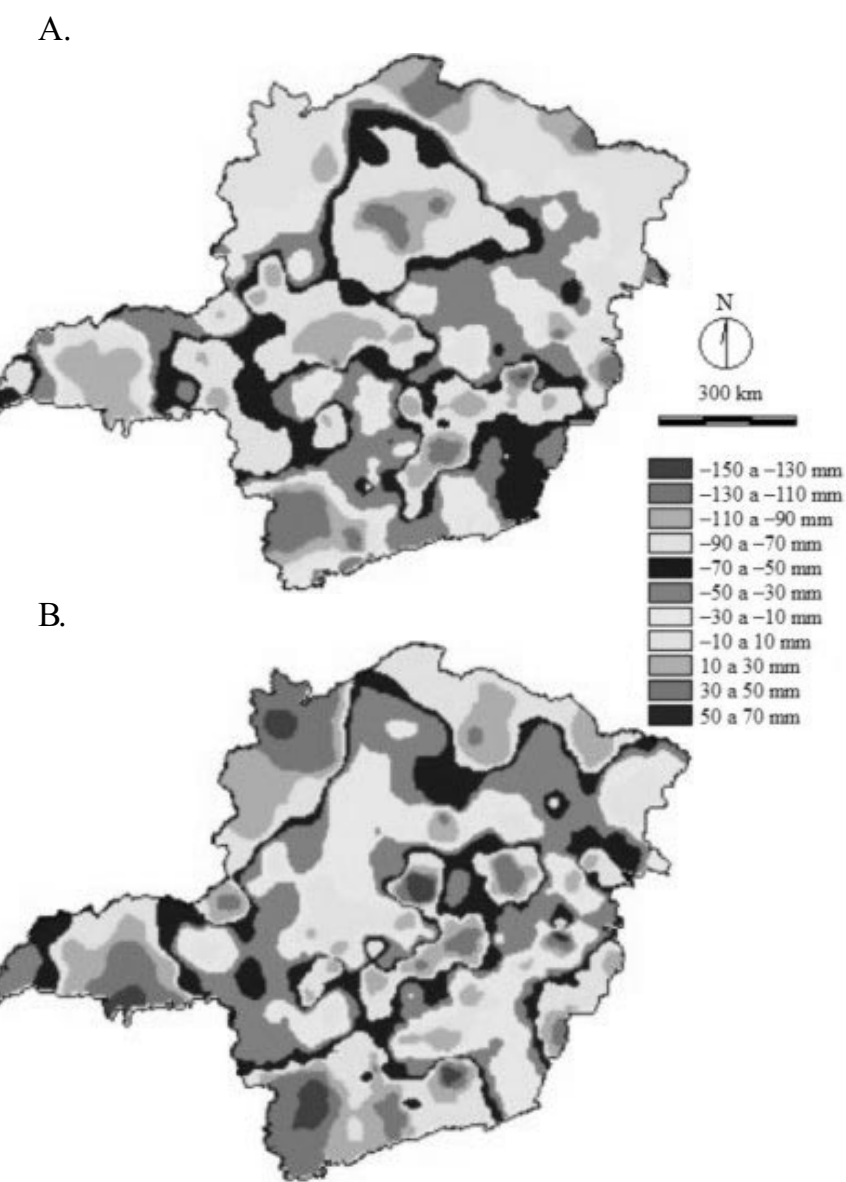

Figura 4. Diferença entre o balanço hídrico de Camargo (1971) e o balanço hídrico diário da cultura do feijão plantado em $1^{\circ}$ de maio de 1999 (A) e em 15 de setembro de 1999 (B)

Tabela 1. Percentagem da área ocupada por classes da diferença entre a demanda de irrigação suplementar calculada pelo balanço hídrico de Camargo (1971) e pelo balanço hídrico diário da cultura do feijão plantado em $1^{\circ}$ de maio e 15 de setembro de 1999

\begin{tabular}{ccc}
\hline Classes $(\mathrm{mm})$ & $\begin{array}{c}1^{\circ} \text { de Maio } \\
(\%)\end{array}$ & $\begin{array}{c}15 \text { de Setembro } \\
(\%)\end{array}$ \\
\hline-160 a -130 & - & 2,0 \\
-130 a -110 & 1,3 & 9,3 \\
-110 a -90 & 5,4 & 12,3 \\
-90 a -70 & 17,5 & 16,7 \\
-70 a -50 & 15,7 & 14,5 \\
-50 a -30 & 17,4 & 20,5 \\
-30 a -10 & 13,7 & 15,5 \\
-10 a 10 & 18,6 & 7,2 \\
10 a 30 & 6,8 & 1,7 \\
30 a 50 & 3,6 & 0,2 \\
50 a 70 & - & 0,1 \\
\hline
\end{tabular}


As grandes diferenças encontradas entre os dois métodos de cálculo da demanda de irrigação estudados podem assim ser explicadas: o balanço hídrico proposto por Camargo (1971) utilizou dados medidos apenas de precipitação, e os demais elementos climáticos foram obtidos por meio de médias de séries históricas, enquanto no balanço hídrico calculado pelo sistema, utilizaram-se apenas dados medidos, inclusive da irradiância solar global, que são elementos muito variáveis e influenciam substancialmente na estimativa da evapotranspiração. O cômputo diário desses fatores permitiu maior exatidão no cálculo do balanço de energia e do transporte de vapor (fator aerodinâmico) na estimativa da evapotranspiração.

Estimativa do volume total de água para irrigação: Na Figura 5 apresenta-se a distribuição espacial dos municípios do Estado de Minas Gerais classificados, conforme a área irrigada, de acordo com o Censo Agropecuário de 1995-1996 (FIBGE, 1998). Observou-se que os municípios com maiores áreas irrigadas estavam concentrados na região Noroeste mineira. A classe predominante, que ocupava $29 \%$ da área do Estado, foi representada pelos municípios que possuíam até 100 ha de seu território irrigado.
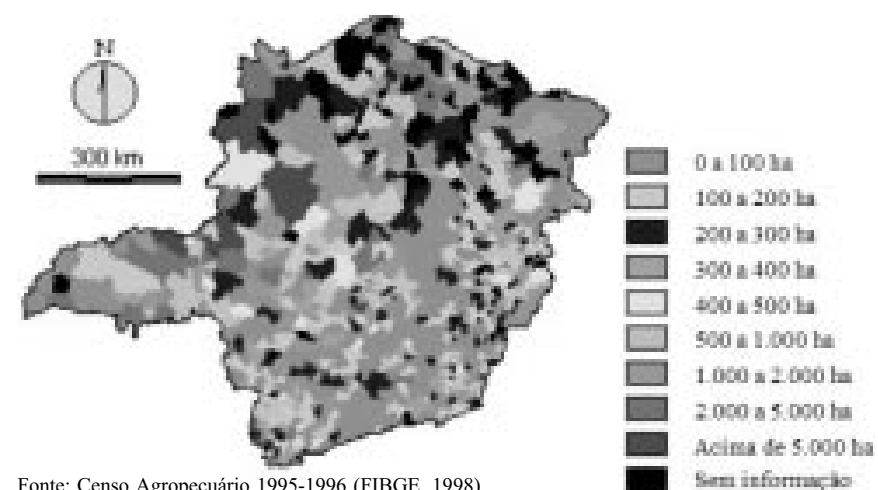

Figura 5. Área cultivada utilizando-se irrigação nos municípios de Minas Gerais

Considerando-se toda a área irrigada do Estado de Minas Gerais ocupada com o feijoeiro, calculou-se o requerimento de água para irrigação por município, em duas diferentes épocas de plantio (Figuras 6A e B). A cultura do feijoeiro foi escolhida por se tratar da principal cultura irrigada do Estado e, também, por não ser disponível informação de área irrigada para cada cultura por município. Analisando-se essa distribuição espacial, não se verificaram grandes diferenças entre os períodos. $\mathrm{O}$ volume total de água requerido para suprir a demanda hídrica da cultura do feijão em todo o Estado de Minas Gerais foi de $611.720 .830 \mathrm{~m}^{3}$ e $686.660 .480 \mathrm{~m}^{3}$, no plantio em $1^{\circ}$ de maio e em 15 de setembro, respectivamente. $\mathrm{O}$ valor ligeiramente mais elevado na estação chuvosa foi devido, provavelmente, à evapotranspiração mais elevada nesse período (Figuras 7A e B). Observou-se que $62,2 \%$ da área do Estado, no primeiro período, apresentou $\mathrm{ET}_{\mathrm{o}}$ na faixa de 260 a $300 \mathrm{~mm}$, enquanto no segundo período o intervalo de maior freqüência $(59,9 \%)$ ficou entre 340 e $380 \mathrm{~mm}$ (Figura 9). Outro fator que pode ter auxiliado na explicação desse fato foi a distribuição das chuvas. No primeiro período, $92,6 \%$ da área do Estado apresentou

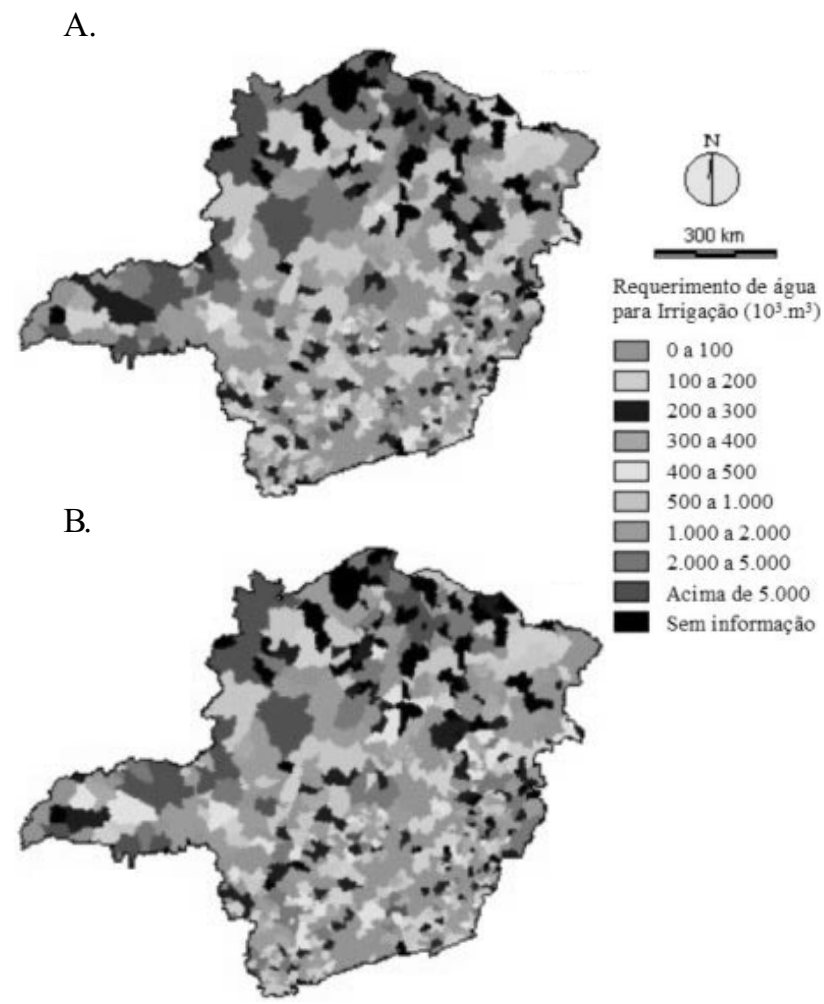

Figura 6. Requerimento de água para irrigação, por município, da cultura do feijão plantado em 1o de maio de 1999 (A) e em 15 de setembro de 1999 (B)

A.

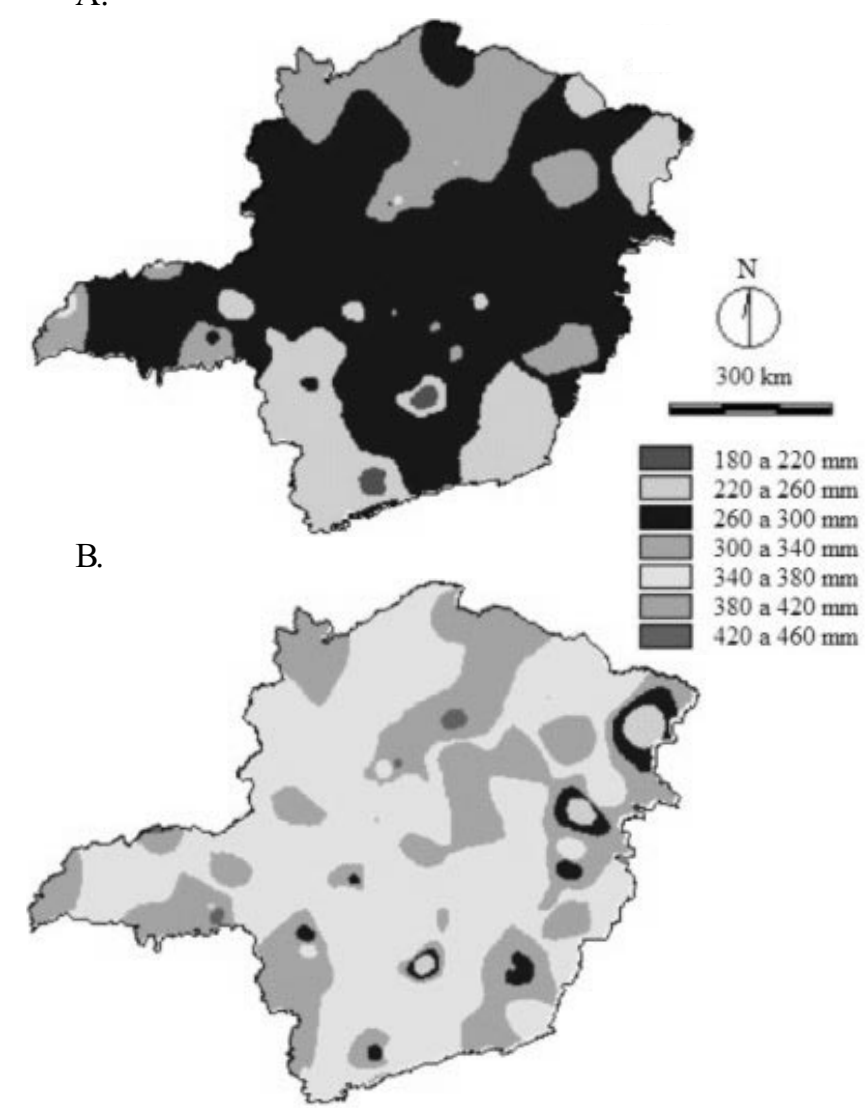

Figura 7. Evapotranspiração de referência acumulada no período de $1^{\circ}$ de maio a 30 de julho de 1999 (A) e no período de 15 de setembro a 14 de dezembro de 1999 (B) 
A.

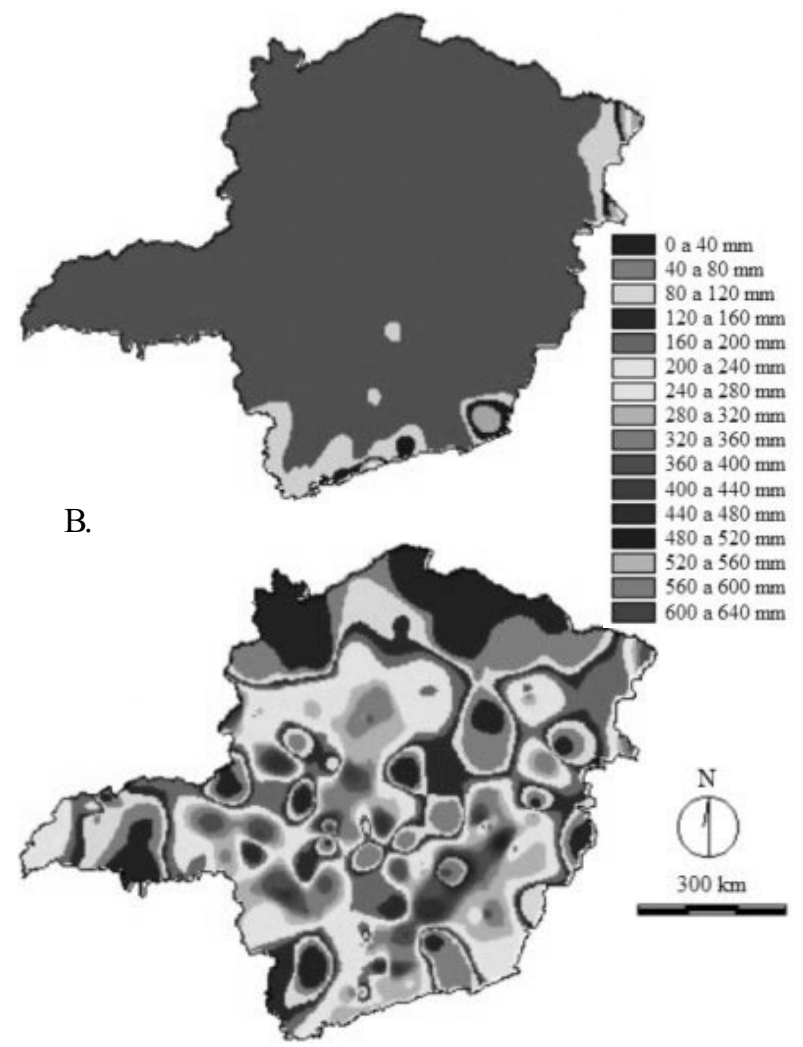

Figura 8. Precipitação acumulada no período de $1 \stackrel{0}{\circ}$ de maio a 30 de julho de 1999 (A) e no período de 15 de setembro a 14 de dezembro de 1999 (B)
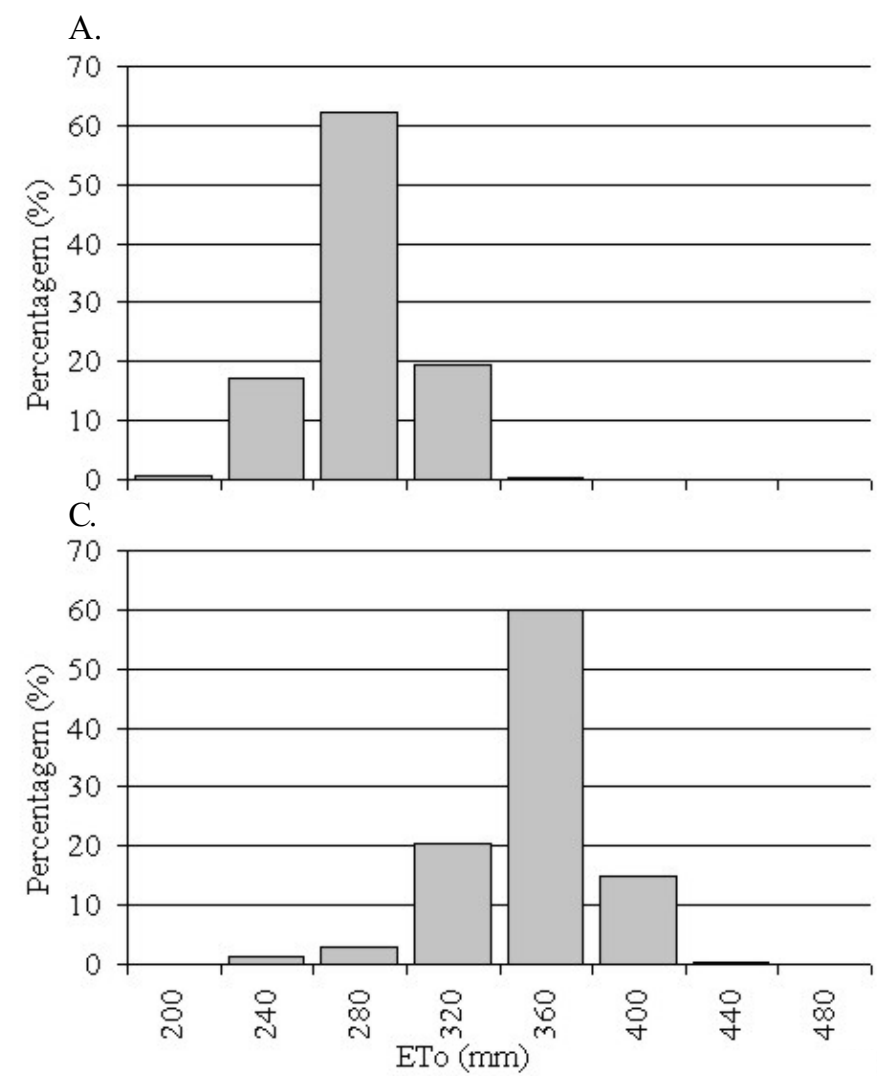

precipitação abaixo de $40 \mathrm{~mm}$, enquanto no segundo, em $86,7 \%$ da área, a precipitação foi maior que $40 \mathrm{~mm}$ (Figuras $8 \mathrm{~A} \mathrm{e} \mathrm{B).}$ Apesar de ter chovido mais no segundo período, o grau de aproveitamento das chuvas foi mais elevado no primeiro período que no segundo. Em outras palavras, observou-se maior número de dias com chuva no primeiro período e se espera que, quanto mais bem distribuídos forem os totais de chuvas no tempo, melhor será o aproveitamento da água pelas plantas.

\section{Comparação da evapotranspiração de referência}

Com o objetivo de mostrar o erro a que se está sujeito ao utilizar o método do Tanque Classe A no manejo de irrigação, fez-se uma comparação entre os métodos de estimativa da $\mathrm{ET}_{0}$ : FAO Tanque Classe A e FAO Penman-Monteith, considerandose este último como padrão, no ano de 1999. Os resultados podem ser observados na Figura 10 e na Tabela 2, que contêm o resumo estatístico da análise de regressão. Verificou-se que o método do Tanque Classe A subestimou a $\mathrm{ET}_{\mathrm{o}}$ em apenas $7,6 \%$, mas a dispersão foi muito acentuada, o que pode ser evidenciado pelo coeficiente de determinação muito baixo $\left(\mathrm{r}^{2}=0,3039\right)$. Notou-se, também, que o erro-padrão da estimativa foi muito elevado (EPE $\left.=1,82 \mathrm{~mm} \mathrm{~d}^{-1}\right)$ mesmo quando a regressão foi ajustada pela origem $\left(E P E A=1,44 \mathrm{~mm} \mathrm{~d}^{-1}\right)$. Apesar do Tanque Classe A ser de simples operação e relativamente de baixo custo e, ainda, por se tratar de um dos métodos considerados padrão pela $\mathrm{FAO}$, é necessário considerar-se os reais benefícios de se utilizá-lo. Caso não seja possível a utilização de outro método de estimativa da $\mathrm{ET}_{0}$ mais preciso,
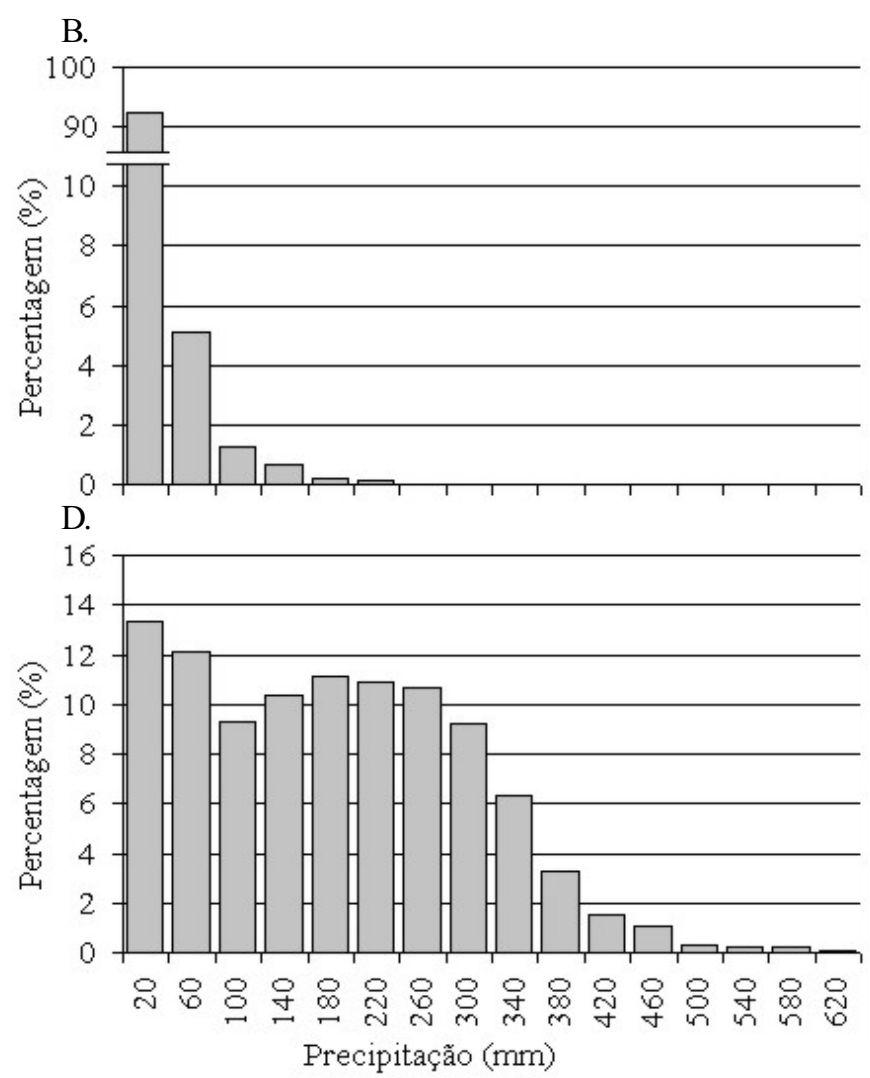

Figura 9. Histogramas de freqüência das classes de evapotranspiração de referência $\left(\mathrm{ET}_{\mathrm{o}}\right)$ acumulada e da precipitação acumulada nos períodos de 1ํ de maio a 30 de julho de 1999 (A) e (B), respectivamente, e de 15 de setembro a 14 de dezembro de 1999 (C) e (D), respectivamente 
deve-se ter cuidado na instalação e manutenção do tanque, evitando erros ainda maiores; também, é recomendável que seja feita a calibração periódica dos valores obtidos com o Tanque Classe A, utilizando-se a umidade do solo medida pelo método-padrão de estufa.

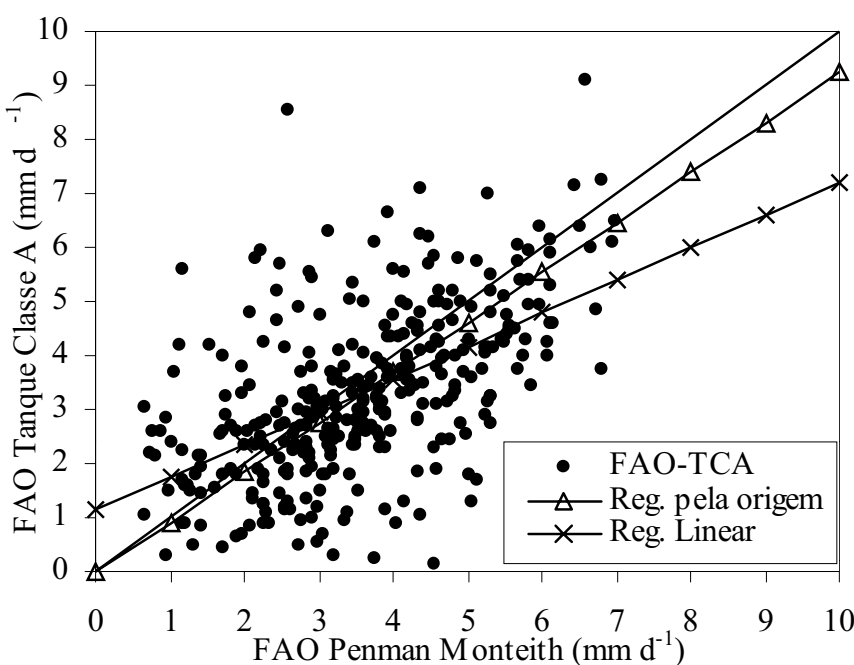

Figura 10. Comparação da estimativa da evapotranspiração de referência calculada pelo método FAO-Tanque Classe A e FAO-Penman-Monteith para o ano de 1999

Tabela 2. Resumo estatístico da análise de regressão da estimativa da evapotranspiração de referência calculada pelo método FAO-Tanque Classe A

\begin{tabular}{lr}
\hline Parâmetro & Valor \\
\hline Média & $3,30 \mathrm{~mm} \mathrm{~d}^{-1}$ \\
Erro-padrão de estimativa (EPE) & $1,82 \mathrm{~mm} \mathrm{~d}^{-1}$ \\
Coeficiente linear da regressão (a) & 1,1277 \\
Coeficiente angular da regressão (b) & 0,6084 \\
Coeficiente de determinação (r ${ }^{2}$ ) & 0,3039 \\
Coeficiente de regressão ajustado pela origem (b') & 0,9239 \\
Erro-padrão de estimativa ajustado (EPEA) & $1,44 \mathrm{~mm} \mathrm{~d}^{-1}$ \\
\hline
\end{tabular}

\section{CONCLUSÕES}

1. O modelo proposto por Camargo subestimou a estimativa da demanda de irrigação suplementar acumulada nos ciclos iniciados em 1을 de maio e em 15 de setembro.

2. O volume total de água para irrigação da cultura do feijoeiro em todo o Estado de Minas Gerais, no plantio de $1^{\circ}$ de setembro de 1999, foi ligeiramente mais elevado que no plantio em $15 \mathrm{de}$ maio de 1999.

3. O método do Tanque Classe A subestimou a evapotranspiração de referência em 7,6\%, mas o erro-padrão da estimativa foi de $1,82 \mathrm{~mm} \mathrm{~d}^{-1}$.

\section{AGRADECIMENTOS}

Agradecemos ao CMCD/INPE, à CEMIG e ao INMET, pela disponibilização dos dados; ao Conselho Nacional de Desenvolvimento Científico e Tecnológico (CNPq) e à Fundação de Amparo à Pesquisa do Estado de Minas Gerais (FAPEMIG CAG 2522/98) pelo imprescindível suporte financeiro para a execução deste trabalho.

\section{LITERATURA CITADA}

Allen, R.G.; Pereira L.S.; Raes, D.; Smith, M. Crop evapotranspiration - Guidelines for computing crop water requirements. Rome: Food and Agriculture Organization of the United Nations, 1998. 300p. Irrigation and Drainage Paper 56

Bergamaschi, H. Agrometeorologia aplicada à irrigação. Porto Alegre: UFRGS, 1992. 125p.

Bernardo, S. Manual de irrigação. 6.ed. Viçosa: UFV, 1995. 657p. Camargo, A.P. de. Balanço hídrico no Estado de São Paulo. Campinas: Instituto Agronômico, 1971. 24p. Boletim 116

Costa, M.H. Modelo de otimização dos recursos hídricos para irrigação conforme a época de plantio. Viçosa: UFV, 1991. 111 p. Dissertação Mestrado

FIBGE - Fundação Instituto Brasileiro de Geografia e Estatística. Censo Agropecuário 1995-1996, v.16, p.1-421, 1998.

Frizzone, J.A. Programação matemática aplicada a projetos hidroagrícolas. Viçosa: Sociedade Brasileira de Engenharia Agrícola, SBEA, 1995. 28p.

INPE - Instituto Nacional de Pesquisas Espaciais. Plataforma de coleta de dados. http://www4.cptec.inpe.br/pcd.htm. Mai. 2003

Knox, J.W.; Weatherhead, E.K.; Bradley, R.I. Mapping the total volumetric irrigation water requirements in England and Wales. Agricultural Water Management, Amsterdam, v.33, p.1-18, 1997.

Reichardt, K. A água em sistemas agrícolas. São Paulo: Manole, 1990. 188p.

Santana, M.O. Sistema de geoespacialização da demanda de irrigação suplementar para o Estado de Minas Gerais em tempo quase real. Viçosa: UFV, 2000. 69p. Dissertação Mestrado

Verma, A.K.; Cooke, R.A.; Hirschi, M.C.; Mitchell, J.K. GIS and GPS assisted variable rate application (VRA) of agrichemicals. Journal of Geographic Information and Decision Analysis, Ontário, v.2, n.1, p.17-22, 1998.

Waskman, G.; Harkin, M. Green telematics from videotex to Internet based applications. Computers and Eletronics in Agriculture, Amsterdam, v.22, p.131-139, 1999. 